\title{
Arte, legislación y política en Lima: siglo XVIII
}

\author{
Martha Barriga Tello \\ Universidad Nacional Mayor de San Marcos
}

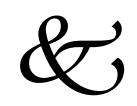

\section{Resumen}

El presente trabajo tiene por objeto establecer las relaciones entre política, legislación y producción artística durante el siglo XVIII en el Virreynato del Perú. Se establecen, así, tres momentos diferenciados en los que el Estado mostró su preocupación por el patrimonio artístico y la actividad vinculada al arte. El estudio se centra en la legislación local y en la peninsular que normaron esta actividad y en el papel que los agentes relacionados con el arte desempeñaron durante ese siglo.

Palabras claves: Arte peruano, Siglo XVIII, Legislación, Política.

\begin{abstract}
Art, legislation and politics: Lima, XIII th century

This article shows the relationship among politics, legislation and artistic production in XVIII th century Peru, at a time when the State, in three specific stages, exhibited its involvement towards our artistic heritage and activities connected to art. It also compares local and Spanish legislation and the role of the agents linked to art.
\end{abstract}

Key words: Peruvian art, XVIII th Century, Legislation, Politics. 
Para entender la complejidad de las relaciones entre la política, la legislación y las manifestaciones artísticas en el Virreinato del Perú en el siglo XVIII debe establecerse tres momentos diferenciados de acuerdo al interés que mostró la Corona por ordenar su administración. Estos momentos son los siguientes: El primero va de 1700 a 1759; el segundo de 1759 a 1788 y el tercero de 1789 a 1808 (Barriga, 2004: 55-56). Cada una de estas etapas significó una preocupación distinta para el Estado en su relación con el arte, siendo la etapa central aquella en la que se emitió la legislación más precisa. En Lima, el sismo de 1746 fue la ocasión que facilitó los cambios.

\section{El sismo de 1746}

El desastre que produjo en Lima y en el Callao fue enorme. El entonces virrey José Antonio Manso de Velasco señaló que

la ciudad sin templos y sin casas quedó hecha un lugar de espanto, a la manera que suelen verse en una guerra los lugares cuando entra el enemigo a sangre y fuego, y convierte en montones de tierra y piedras los más hermosos edificios. (Moreno, 1983: 259)

Debido a su magnitud, el terremoto de 1746 supuso la reedificación o la restauración de los monumentos más representativos de la ciudad. En el contexto de la época se estaba produciendo una nueva actitud respecto a las características formales que, desde la Corona española, se extendía al territorio de su imperio. Las disposiciones que dictó respecto a la apariencia que debían tener tanto los edificios como los elementos muebles en ellos, orientaron la labor de los comitentes oficiales, civiles y religiosos y, por tanto, la de los artífices que convocaron.

Fue de tal severidad el daño, que los artistas eran requeridos en competencia, por lo que los precios se elevaron considerablemente. Los materiales constructivos y la mano de obra alcanzaron niveles notables. No detuvo esto la reconstrucción de la ciudad, aunque si determinó la selección de los materiales. Tanto por razones económicas, como de seguridad constructiva, se adoptaron medios estructurales que, después de la comprobación posterior al terremoto, se calificaron como adecuados a la zona. 
El virrey José Antonio Manso de Velasco tuvo una decisiva participación en la reconstrucción de Lima, concertando con especialistas y con el Cabildo las medidas más adecuadas para ser aplicadas en las nuevas edificaciones.

La reconstrucción de la ciudad también supuso cambios patrimoniales que afectaron a los ciudadanos. Muchas familias, alertadas por el terremoto y ante el peligro que representaba continuar residiendo en sus propiedades, optaron por abandonar la ciudad. Esta fue ocasión para que los terrenos fueran ocupados por otros ciudadanos, quienes iniciaron trabajos de construcción en ellos, aunque también fue importante el número de los que al momento estaban habitando viviendas improvisadas con maderas en las calles y plazas de la ciudad. El saqueo consecuente al desastre involucró a todos los sectores sociales. Incluso se denunció al propio virrey de apropiarse de objetos dejados en la playa del puerto del Callao cuando se retiraron las aguas que, prácticamente, lo sepultaron por un sunami que sobrevino a consecuencia del sismo.

\section{La construcción de los templos y su contexto}

Conocemos que la riqueza que mostraban los templos brindaba reconocimiento a la orden religiosa, al comitente que había participado como donador de alguna sección del edifico, retablos o imágenes, tanto como a las familias cuyos miembros se habían integrado a las congregaciones y ocupaban cargos en alguna de ellas. En ciertas familias y derivado de diversas circunstancias, varios, cuando no todos los hijos varones y mujeres, eran religiosos de alguna de las órdenes. El reconocimiento social y el sustento de la dignidad de los individuos, que se evidenciaba en los elementos externos o en sus lugares de devoción o enterramiento, fue un notable estímulo para la generosidad de las donaciones.

En este contexto se identifican sectores directamente involucrados en el rumbo que tomaría la reconstrucción respecto a los intereses que afectaría. Paralelamente, en los sectores mayoritarios de clientes y artífices, la tendencia estilística del siglo no se había modificado sustancialmente. Fue en aquellos en los que, por diversas circunstancias, se tuvo que retrasar la reconstrucción, o en los casos de las congregaciones que gozaron de disponibilidad económica, en los que 
en el último tramo del XVIII se produjeron cambios significativos en sus elementos ornamentales y muebles. De acuerdo a la política del Estado la pintura y la escultura y a partir de ambas el retablo, debían integrarse eficaz y coherentemente en un todo expresivo y de alabanza divina orientados a comprometer y educar a los fieles desde su simplicidad y limpieza formal, evitando los excesos que elevaran los costos y sobretodo aquellos que significaran quebrar el canon aceptado como clásico. El Marqués de Ureña en Reflexiones sobre la Arquitectura, ornato y música del templo (Madrid en 1785), opinaba acerca de la ornamentación arquitectónica que

$$
\begin{aligned}
& \text {...jamás los ziczaques adornos ni relumbrones harán una cosa buena } \\
& \text { mientras esencialmente no lo sea, porque los adornos son parte } \\
& \text { accidental y no esencial de la belleza y nunca parece más irrisible un } \\
& \text { hombre contrahecho que cuando está muy engalanado (...) aún diré } \\
& \text { más, que los adornos sin elección ni discreción desgraciarían } \\
& \text { infaliblemente una obra auque esencialmente sea buena. (León-Sanz, } \\
& \text { 1994: 1101) }
\end{aligned}
$$

Más decidido se mostró con los retablos en los que el barroco y el rococó habían depositado lo más creativo de sus formas: "Qué deformidad en los retablos!, iQué relumbrones tan vacíos!, iQué frivolidades tan ajenas de la seriedad del templo!» (León-Sanz, 1994: 1101) Ureña es un ejemplo, entre otros, de la presión continua que ejerció la postura ideológica extrema de rechazo a lo que hasta entonces -y en muchos espacios todavía- correspondió a la formalización cristiana. El resultado del enfrentamiento en las opiniones que defendían quienes debían orientar la política artística hispana, fue la confluencia en un mismo edificio de varios estilos, hecho que fue aceptado sin análisis crítico, a pesar de que la estética ilustrada propendía a la unidad, uniformidad, armonía y simetría, lo que era subvertido en la combinación y en la propia aplicación de los elementos plásticos. Un eclecticismo inevitable caracterizará las obras de arte así como los templos de la época en España y América.

\section{Actantes en el proceso}

Un aspecto concomitante al desastre y por extensión a cualquier proceso constructivo urbano, corresponde a los responsables de la 
reconstrucción. En primer nivel el Estado, metropolitano y local, como emisor y controlador de la legislación general y particular que debía aplicarse; el segundo los comitentes civiles y religiosos defensores de sus propios intereses además de estar más o menos comprometidos con las autoridades, y el tercero, de actuación más libre, que eran los operarios y artífices así como los proveedores de materiales e insumos, que podrían identificarse como los sobrevivientes, beneficiarios directos del sismo. Para todos ellos debían establecerse normas las que, paralelamente, serían reflejo de la política general del Estado. Se señala que a propósito del terremoto del 46 , los proveedores y los alarifes gozaron de una época de prosperidad porque el trabajo abundaba y los salarios subieron tanto como el precio de los materiales que debieron utilizarse en la reconstrucción. No se quedaron atrás los comitentes, pues últimos estudios hacen hincapié en el interés de los damnificados por abultar las cifras para sustentar sus daños con el propósito que les sirviera para justificar los préstamos respecto a la inversión que debían realizar en la reconstrucción. Se consideran entre estos, además, la cantidad de inmuebles que se encontraban sujetos a censos cuyos beneficiarios eran los religiosos, en especial las órdenes femeninas. (Pérez-Mallaína, 2001: 72, 78) Este sector no se marginó de las ganancias vinculadas a la preparación y distribución de los materiales que se emplearon para recuperar la ciudad, en especial la Compañía de Jesús que vendió adobes, ladrillos y cal con grandes utilidades. (Pérez-Mallaína, 2001: 78) A ello se sumó la participación de la Iglesia como contratante y cliente prioritario de los artífices para reparar sus propias instalaciones, y la presión que estaban en condiciones de ejercer en perjuicio de los particulares. Esto motivado por dos circunstancias que coinciden en el mismo actor.

a) Aquella que se orienta a solucionar problemas internos de procedimiento y

b) Otra que intenta cumplir con las normas borbónicas.

\section{A. La legislación local en el contexto de la ciudad}

Las medidas correctivas que decidió aplicar la administración central para las nuevas construcciones, en contra de la planificación anterior 
que obvió que Lima estaba situada en zona sísmica, recibieron una fría, cuando no violenta reacción por parte de los afectados. El primer rechazo fue contra la propuesta de derribar los segundos pisos de las viviendas que habían sido levantados en adobe, un material considerado excesivamente pesado para soportar cualquier otro desastre que sufriera la ciudad. Se dispuso que los muros se reemplazaran por caña-quinchay se emplearan techos de madera. Otro tanto se normó para los edificios religiosos, aunque su altura no había superado en exceso los civiles, con el añadido de prohibir las torres en favor de las espadañas.

\section{Las consecuencias político sociales}

Como suele ser frecuente en situaciones extremas, el problema se extendía más allá de lo formal. Un terremoto de la magnitud del de 1746 significó posibilidades de ganancia enormes para los artífices y para los comerciantes. Para evitar la especulación fueron emitidas disposiciones acerca de los precios de los materiales de construcción así como los montos adecuados que se pagaría a los artífices y jornaleros. Duraron poco estas disposiciones pues las autoridades debieron revocarlas ante la protesta pública. Fue evidente que los perjudicados sumaban mucho más que los beneficiados y que, además, por su posición de privilegio, tenían capacidad para reconvenir al virrey. Aunque no debe olvidarse la intención implícita de selección social que entrañaban las normas, hay que aceptar que fueron necesarias para regular situaciones resultado del caos después del desastre, como el exceso en los cobros por los materiales, su acaparamiento por los intermediarios (llamados «regatones» en España) y los altos jornales que exigían los artífices.

\section{B. Legislación peninsular}

Un referente al que pueden remitirse las medidas tomadas en Lima para el orden interno fue la legislación que en la España contemporánea reguló el trabajo de los especialistas, así como obstaculizaba la posibilidad de fraude. Al problema que creó la Corona a los maestros y arquitectos, por la obligación que tenían de presentarse y aprobar un examen ante las recientes autoridades académicas para refrendar u 
obtener los títulos que les permitirían ejercer sus oficios, se añadió los cuestionamientos a su conducta ética basados en situaciones denunciadas que no eran exclusivas de la Península. Había quienes firmaban monteas, o cobraban, por el trabajo de quienes no poseían el permiso oficial por no haber aprobado los exámenes; y aquellos que timaban a los clientes requiriéndoles sumas exageradas o entregándoles trabajos de baja calidad, con el agravante que mantenían ocultas las faltas exponiendo a grave peligro a los habitantes. En todas las profesiones se produjo el fenómeno, pero en ninguna se ponía en riesgo la seguridad del ciudadano como en la construcción. De manera que, tanto en España como en el Perú, se buscó establecer pautas para determinar valores justos para los salarios y para los materiales de construcción así como para poner coto al abuso de las corporaciones o de los particulares que los acaparaban, lo mismo que los encargos.

Un ejemplo de la comunidad de problemas que debían enfrentarse en ambos continentes, en esta oportunidad en relación al fraude, figura en el título 44 de las Ordenanzas de Navarra que puede aplicarse con propiedad a Lima. Se señala que

...porque muchos oficiales toman a su cargo obras igualadas en cierta y
determinada cantidad y después de acabadas hacen estimar las obras a
otros oficiales del mismo oficio, los cuales se ayudan unos a otros en la
estimación y pretendiendo que quedan engañados si no se les paga más
de la iguala piden el exceso de la estimación y muchas veces acaese
suceder de esto inconvenientes y fraudes y pleitos, por tanto mandamos
que los maestros y oficiales de carpintería, albañilería, cantería, pintores
y todos los demás oficiales de otra cualquiera cualidad no puedan
impedir ni puedan ni se les pague por las dichas igualas más de la
cantidad en que se igualaron, aunque haya notable exceso en el valor y
estimación de las obras. (León-Sanz, 1994: 812)

La colusión para el fraude se producía igualmente en la capital del virreinato peruano, de lo que dan cuenta los contratos en los que se advierte que de comprobarse este hecho, quedaba bajo la responsabilidad del maestro sin perjuicio del contratante, pues muchas veces este no encontraba qué vender para cubrir una obligación que había sido generada por la aparente largueza del maestro. También se buscaba proteger la inversión cuando el maestro debía cubrir en su integridad los gastos que significara rehacer una obra mal hecha, ya 
fuera en artes plásticas o arquitectura. Este último caso era frecuente porque los artífices solían firmar más contratos de los que podían cumplir. De ello resultaba que, o los avanzaba todos lentamente de manera paralela excediendo los plazos estipulados en los contratos, o se dedicaba a los más significativos destacando a sus oficiales o aprendices para los otros. Cuando en un contrato se especificaba «que no levante mano de la obra hasta acabarla sin perjuicio de...», no era un mero formulismo, sino una advertencia que buscaba adelantarse a una posible postergación.

En el marco de la política del Estado se dictó otro tipo de disposiciones, a las que hacen referencia las Ordenanzas de Cádiz, que tendrían una trascendencia mayor y que vincularon soluciones locales a normativas más significativas. Estas se enmarcaron, aunque finalmente la superó, en la controversia suscitada entre los gremios y la Academia entre 1776 y 1777, a propósito de la titulación como requisito para ejercer actividades artísticas, especialmente las referidas a los retablos y a la arquitectura, cuya solución llevó implícita la confirmación de su obligatoriedad. Nombrado Antonio Ponz como Secretario de la Real Academia de San Fernando, remitió al rey la Representación de los consiliarios del 10 de agosto de 1777, que se formalizó posteriormente con los Reales Decretos de noviembre del mismo año. Una circular del conde de Floridablanca del 29 de noviembre de 1777, recordó a los Arzobispos y Obispos que: «la reverencia, severidad y decoro debidos a la casa de Dios», los obligaba a consultar con la Academia cualquier proyecto arquitectónico que se quisiese edificar en sus diócesis. (Menéndez y Pelayo, 1944: IX, 131) Por el mismo decreto fue prohibido que en templos o en cualquier otro lugar, se permitiese la existencia de: «retablos como aquellos bárbaros mudéjares afrentosos de la nación e indignos de la casa de Dios» ${ }^{1}$. Por excepción se extendió disponer que los altares no se "hiciesen de ridículos maderámenes sino de mármol o piedra», jaspe o incluso recurriendo a su imitación con estuco, aduciendo la necesidad de preservar los monumentos de los incendios que se producían por el contacto de la madera y las velas. Sin embargo, el 24 de junio de 1784 , a propósito de darle el mismo encargo a la academia de San Carlos de Valencia y en alusión a las protestas, se aclaraba que «no fue 
su Real intención prohibir absolutamente el uso de ellas [las maderas] en aquellos casos en que no están próximas a incendio" por lo que se derivaba la responsabilidad a la Academia. Esta tendría la potestad de establecer la posibilidad del desastre, así como de observar si la obra estaba en concordancia con «las reglas del buen gusto y sólida arquitectura, procurando se imiten a piedras o estucos», e incluso proponer un diseño alternativo de acuerdo a sus estipulaciones. Tres años después el conde de Floridablanca transmitió que el rey favorecía "se promueva el uso de mármoles y estuco siempre que sea posible», haciendo llegar, paralelamente, un tratado sobre la manera de fabricar «estuco jaspeado». (León-Sanz, 1994: 183; García, 1998: 85-88)

\section{La intención detrás de la norma}

Hay más de un hecho que destacar en esta situación. En primer lugar las medidas adoptadas llevaban explícitamente la voluntad de corregir prácticas profesionales y de edificación inadecuadas para el medio geográfico pero, implícitamente, y así fueron percibidas por la población, también eran un pretexto para aplicar una jerarquización acorde con la condición del comitente. Era comprensible la desconfianza de los habitantes perjudicados pues en otros aspectos, como en determinada moda en el vestido, calidad de las telas y de adornos o en llevar armas propias, los borbones se mostraron restrictivos y controlistas, profundamente interesados en mantener las distancias y evitar la oportunidad de movilidad social que el portar alguno de estos elementos conllevaba, a pesar de que fueron más que flexibles en el destino de los muchos títulos nobiliarios que otorgaron por venta. Por otra parte, el propósito de las normas de Carlos III formó parte de un programa ideológico que se aplicó en varios ámbitos y se extendió rápidamente allí donde fue posible y que reflejó la posición de la crítica ilustrada decidida a marginar lo sobrenatural como valor a fines del siglo XVIII. (Egaña, 1966: 824) Esto implicaba negar la religiosidad popular y las manifestaciones pías cercanas a la cultura tradicional que las representaciones vigentes concretizaban. Las expresiones religiosas fueron atacadas por indecentes o inapropiadas y se vinculó el estilo con una presunta declinación de las costumbres y la perversión 
moral. Hipólito Ruiz en Relación histórica del viaje al Perú y Chile. 17771788, se refirió al mismo tema cuando describió las iglesias limeñas: «Da lástima el ver gastados inmensos caudales en atibarlas de cedros y maderas diferentes, embarazándolas con unos que se llaman retablos no siendo otra cosa que monstruosidades del arte y descalabros del buen gusto». (Harth-Terré, 1948)

\section{Legislación y proyecto del Estado}

La legislación referida a edificaciones y otros aspectos de la producción artística, plástica y arquitectónica emitida por la corte borbónica, tuvo carácter general para el territorio bajo su dominio y formó parte de un intento de modernización administrativa del reino sustentada en una percepción prejuiciosa de la tradición hispana, al que se adscribieron intelectuales y políticos contemporáneos que, en su mayoría, habían tenido experiencia francesa o italiana. En España no siempre esta nueva administración supuso una novedad. En algunos casos se tienen Ordenanzas municipales anteriores pero coincidentes con la política del Estado, que fueron reimpresas y otras que se crearon o dieron lugar a leyes reales específicas. En 1792 se establecieron en Cádiz las Ordenanzas de policía que previene todo lo que se debe observar en la fábrica y construcción de los edificios. Obligaciones del Maestro Mayor y Alarifes, y lo que se ha de practicar con los que se reciban de maestros de Obra de Albañilería y se acota que "[Cádiz] se distingue en seguir las justas disposiciones prevenidas en la Orden de S.M. comunicada el 25 [firmada el 23] de noviembre de 1777 y otras posteriores», justas disposiciones que no eran más que reprimir toda formulación ajena a los principios ilustrados. (León-Sanz, 1994: 449) Por entonces Cádiz era el principal puerto de salida hacia América y su influencia era evidente.

\section{Formulación teórica}

El elemento rector, inspirado en la tradición clásica a través de su interpretación renacentista, fue la finalidad práctica ligada a la belleza estética, lo que supuso el predominio de la pureza de la línea; la relación apropiada forma / contenido; la apreciación de los materiales en su 
adecuado uso y posibilidades de expresión, y a la sobriedad que permitiera resaltarlos. En este contexto, la ornamentación arquitectónica se convirtió en factor de apoyo con el objetivo de destacar los valores plásticos y arquitectónicos puros, antes que a desarrollarse por sí misma, como sucedía en el estilo imperante al que se le reprochó haber desfigurado sus soportes y estructuras.

Desde la segunda mitad del siglo XVIII se buscó la exactitud, la precisión y la economía de motivos, tomados de preferencia de la arquitectura misma. Paralelamente, la tendencia fue el conferirle sentido simbólico de modernidad y eficiencia a la organización estructural / ornamental, coherente con el afán normativo que se auspició para todas sus expresiones. Resultado de esto fueron las incongruencias y el eclecticismo del que adolece el arte de la época pues, aunque los teóricos declaraban aspirar al mismo ideal, mostraron posturas totalmente dispares acerca de aspectos puntuales de formalización y propusieron soluciones encontradas referidas, o inspiradas, en las características estilísticas que, supuestamente, eran las que rechazaban. Una postura que se advierte declarativa antes que de aceptación cabal. Sin embargo, hay que reconocer que en una opinión todos coincidieron: su abominación por el estilo vigente como expresión general de confusión, decadencia moral e ignorancia.

Mediante la confrontación de las formalizaciones arquitectónicas con los planteamientos legales y teóricos de la segunda mitad del siglo XVIII limeño, puede comprenderse algunos de los lineamientos estilísticos de la época. La arquitectura es la manifestación en la que más claramente se advierten las propuestas del Estado y de la Iglesia, los dos poderes que buscaron asentar su presencia preeminente en la capital virreinal. Los medios formales de la arquitectura revelan la anuencia, o el rechazo, de los sectores sociales frente a la normativa. Las medidas correctivas de carácter administrativo están vinculadas directamente a los postulados ilustrados, aunque se propongan en aspectos aparentemente colaterales. El control de los salarios, del mercado de materiales y de la manera como debían utilizarse, así como las disposiciones tendientes a regular los contratos y la libre competencia, superaron los límites de las normas pues, finalmente, de lo que se trataba era de mantener bajo el control de las autoridades 
administrativas del Estado los variados aspectos que comprometían la actividad artística. Un sector que participó de la dirección política del Estado, la Iglesia, en gran parte fue consecuente con su actividad general en el territorio americano, adscribió las pautas ilustradas y resultó entusiasta detractora del que hasta hacía escaso tiempo era su lenguaje plástico, una decisión que tuvo más de política institucional que de convicción estética, especialmente en las principales órdenes religiosas, y que evidencia la connotación que tenía el aspecto que adoptaran las manifestaciones artísticas respecto a la aceptación o rechazo del poder del Estado.

\section{Formalizaciones}

En el siglo XVIII, la corriente contra los estilos imperantes se inició con fuerza entre los teóricos españoles que compartieron las ideas ilustradas. En 1776 Diego de Villanueva publicó La Colección de diferentes papeles críticos... en los que inauguró la cruzada que con eficacia continuó Antonio Ponz en los extensos viajes que realizó por el territorio español. La formación profesional en artes, incluyendo la arquitectura, ya estaba definida desde 1752 con la creación de la Real Academia de San Fernando. Es por ello que los arquitectos que por esos años pasaron a América debieron contar con los estudios de la profesión de acuerdo a la directiva de la Academia o, cuando menos, haber tenido contacto con quienes, desde la nueva orientación estilística, conducían los proyectos.

La tendencia clásica ilustrada del arte en Lima en el periodo que tratamos supuso una reorientación signada tanto por la normativa que emanó de la Corona española, como una adaptación a las condiciones que a su vez señalaban los intereses de los usuarios, y el peligro telúrico de la región en la que estaba asentada la capital del Virreinato Peruano. Se advierte que las construcciones oficiales presentaron una marcada tendencia hacia la sobriedad, evitando aquellos elementos que anteriormente habían contribuido a caracterizar la arquitectura limeña, con una organización muraria ordenada apoyada y/o sustentada en soportes discontinuos de carácter clásico sobre pedestal que, de preferencia, se vinculan con entablamentos corridos de ligero 
pronunciamiento, que soportan el friso y la cornisa, conjunto que, en ocasiones, aparece asociado con arcos de medio punto. Los aparejos son uniformes y se recurrió a los soportes tanto adosados como ligeramente exentos, para producir un efecto de claroscuro controlado. Apoyó esta intención la aplicación de festones, guirnaldas, vasos, jarrones y ánforas dispuestos en concordancia con la distribución de los paños.

\section{Retablos}

En opinión del Secretario de la Real Academia de San Fernando los retablos en su tiempo representaban

disparatadas máquinas de madera con el nombre de altares de talla, [contra las] fábricas extravagantes y faltas de artificio [de esos] promontorios desatinados y bárbaros [con ese] modo costoso y quimérico de edificar [en esos] templos dignos de los pueblos de Scythia (...) los cornisamentos rotos, frontispicios dentro de frontispicios, de esos cuerpos multiplicados sobre un mismo plano, de esas pilastras y columnas agrupadas para no sostener cosa alguna, de esas líneas tortuosas, y, finalmente, de esos miembros que no se puede atinar lo que significan ${ }^{2}$.

Opiniones como la suya eran suscritas por sectores de opinión implicados en las decisiones que en la época condujeron a la construcción, adaptación o sustitución de los retablos que ocupaban las capillas en la mayor parte de las iglesias limeñas. De acuerdo a lo dispuesto por Carlos III el 23 de noviembre de 1777, se prohibió la construcción de retablos, muebles o techos de madera, bajo la consideración de la alta tasa de incendios que el descuido en el uso de las velas había producido. Se agregaba que tampoco podrían dorarse debido al alto costo que ello representaba. Esta prohibición se extendió a la escultura policromada y dorada en nuevos decretos de 1778 y 1786, debiéndolas reiterar Carlos IV para ambas prácticas, en 1791 (Bruquetas, 2003: 17) ${ }^{3}$, por la escasa respuesta que recibieron. En los decretos iniciales la Corona brindó la opción de trabajarlos con mármoles, jaspes u otras piedras y posteriormente señaló que, de ser escasos, podrían sustituirse con imitaciones. Algunos artífices propusieron materiales alternativos, como la arcilla que Francisco Albella presentó a la aprobación de la Sociedad Económica de Zaragoza por haberla aplicado con éxito en un capitel y una cornisa (León-Sanz, 
1994: 451), pero más frecuentemente fue el yeso la solución que permitió cubrir en gran parte las necesidades ornamentales ${ }^{4}$ por sus posibilidades de combinación, contempladas en la misma legislación. En atención a lo estipulado, allí donde no era posible contar con los originales por costos o disponibilidad, con frecuencia se imitó con pintura la calidad de materiales como el mármol y el jaspe, tanto para los paños como para los soportes. Aunque no podemos extender esta opción a todo el corpus arquitectónico en Lima, si fue aplicada por lo menos en porcentaje significativo en las iglesias mayores de las principales órdenes religiosas en los elementos de sustento, cubierta y en los retablos. Entre los tratados europeos de la época que intentaron apoyar el cumplimiento de las normas a bajo costo, proponiendo fórmulas y procedimientos, están el de R.P. Diez, El arte de hacer el estuco jaspeado (Madrid, 1785) y el de Genaro Cantelli que ofrecía variadas posibilidades para fabricar barnices y policromar materiales para resaltarlos, o enmascararlos, con una apariencia más rica. (LeónSanz, 1994: 742) Por los resultados que se consignan en algunos monumentos fue evidente que no siempre se pudo confiar en la idoneidad de los artífices para obtener estos enmascaramientos, que los viajeros del siglo XIX en Lima advierten como burdas imitaciones de mal gusto.

\section{Aspecto general}

La nueva concepción estilística pretendió erradicar toda referencia a la apariencia anterior como los volúmenes pronunciados y dinámicos, en favor de la sobriedad de la línea recta de escasa proyección. Los dorados quedaron reducidos a elementos mínimos de adorno o a resaltar algunos de carácter arquitectónico para contribuir al ordenamiento general de los cuerpos en los retablos. Con frecuencia encontramos que se asocian a colores complementarios, especialmente los fríos como el azul y el verde turquesa, principalmente en diseños geométricos que aluden a formas arquitectónicas. El remate suele ser equilibrado al conjunto, siguiendo un diseño de frontón triangular o de arco de medio punto cerrados, así como de bóveda semiesférica, según los casos. Actualmente gran parte de los ejemplos a los que podríamos remitirnos han perdido su aspecto original debido a 
intervenciones posteriores, pero los que permanecen y fueron mantenidos, nos informan lo que, en conjunto, presentaron. En ocasiones se prefirió sobredorar las columnas ya fuese en el fuste, en el capitel o en ambos, y esgrafiarlas. El análisis de los retablos que hemos estudiado señalará tipologías que, en términos generales, pueden remitirse a la fórmula b-A-b, en la que la sección central destaca con respecto a los laterales, cualquiera sea la modalidad por la que se optara en el conjunto. Observamos en nuestro medio, y en la especulación teórica española, la preocupación por definir el estilo de la época sin considerar que, las mismas contradicciones que se advierten en la normativa, están reflejadas en la formalización artística. La indefinición que supuso el enfrentamiento con la opinión pública hizo inviables muchas de las pautas signadas en las leyes. Los clientes, por su parte, se resistieron a aplicarlas en la península y en América porque emanaban de una autoridad que pareció ignorar la condición peculiar de los pueblos que gobernaba. Identificar, por lo tanto, un marcado eclecticismo en lo realizado entonces no debe sorprender, antes bien debe encontrarse mecanismos de análisis para comprender la problemática de la época en el contexto de la creación artística sin ajustarla, necesariamente, a las categorías presumiblemente aceptadas como indiscutiblemente válidas, mucho menos factibles en periodos de transición y de enfrentamientos políticos e ideológicos.

El proceso de reconstrucción después del terremoto de 1746 y las edificaciones posteriores correspondientes al periodo que tratamos, confrontó a todos los sectores sociales con capacidad de decisión respecto a los asuntos que involucraban a la ciudad, incluyendo el apoyo y determinación de la apariencia de las edificaciones religiosas. En casos extremos como los de desastres naturales, el arte tanto se beneficia como se perjudica. Se beneficia porque obliga a tomar decisiones que en otras circunstancias son difíciles de consensuar y porque, intentando protegerse frente al mundo sobrenatural, los donantes suelen ser generosos, sin escatimar gasto alguno en el mejor servicio de sus creencias religiosas. Pero, igualmente, el mismo desastre destruye tanto a las obras como a los más conspicuos comitentes y artistas, por lo que quienes permanecen activos no siempre están en capacidad de alcanzar el objetivo primario de igualar o superar una 
obra perdida. El fervor y el orgullo, aparejados a la capacidad económica de los comitentes también suponen, con frecuencia, que se tomen decisiones apresuradas respecto a lo que se ha de preservar y el estilo de aquello que sustituirá lo destruido, en el esfuerzo por mantener la prestancia y esplendor anterior de los monumentos y su entorno sin transgredir las normas oficiales. Esta preocupación muestra una carta del Conde de Casa Jirón en Lima al afirmar que, «aunque no sea por propia comodidad y gusto, estamos [...] precisados a conservar la decencia necesaria para que no se burlen los émulos». (Flores Galindo, 1984: 79) En este contexto, los enfrentamientos y aspiraciones personales de la Iglesia y el Estado en su representante local y en lo referido a las intenciones de control de la Corona, no hicieron más que profundizar las contradicciones que se vieron reflejadas en la producción artística de la época. El conflicto estaba planteado y las expresiones artísticas, fieles a su tradición, lo reflejaron.

\section{Notas}

\footnotetext{
Por mudejar se hacía referencia al estilo barroco representando en la columna salomónica denominada «mosaica», tal como figura en contratos de la época: RODRÍGUEZ G. DE CEBALLOS, Alfonso. Joaquín de Churriguera y la primera cúpula de la Catedral Nueva de Salamanca. En: Homenaje al profesor Martín Gonzáles. Valladolid, Universidad de Valladolid. Secretariado de Publicaciones, 1995 (249-260): 250.

2 MENÉNDEZ Y PELAYO 1944: IX, 127 y 129: Viaje de España, en que se da noticia de las cosas más apreciables y dignas de saberse que hay en ella. Madrid, Imprenta de Ibarra, 18 tomos publicados entre 1772 y 1794 . A Ponz se debe el término «plateresco» para señalar estas características. Su obra fue continuada, aunque con alcances más restringidos, por Isidoro Bosarte, su sucesor en la Secretaría de la Academia y a Eugenio Llaguno y Amírola y sus Noticias de los arquitectos y arquitectura de España, publicada después de 1829 con adiciones de Juan Agustín Ceán Bermudez, siendo las tres fuente documental indispensable para la época.

3 Tanto en la mezcla de yeso (yeserías) como de cal (estuco) y sus combinaciones de color (escayola) que permitían la simulación del mármol.
}

\section{Referencias bibliográficas}

BARRIGA TELLO, Martha (2004): Influencia de la Ilustración borbónica en el arte limeño: siglo XVIII (Antecedentes y aplicación). Fondo Editorial de la Universidad Nacional Mayor de San Marcos, Lima.

BRUQUETAS, Rocío, Ana Carrassón y Teresa Gómez Espinosa (2003): «Los retablos, conocer y conservar». Revista del Instituto del Patrimonio Histórico Español, No 2, Madrid. 
EGAÑA, Antonio de (1966): Historia de la Iglesia en la América Española. Hemisferio Sur. Biblioteca de Autores Cristianos, Madrid.

FLORES GALINDO, Alberto (1984): Aristocracia y Plebe. Lima 1760-1830. Mosca Azul Editores, Lima.

GARCÍA MELERO, José Enrique (1998): Arte Español de la Ilustración y del siglo XIX. Ediciones Encuentro, Madrid.

HARTH-TERRÉ, Emilio (1948): «Lima en 1788». En El Comercio, Lima, 28 de julio.

LEÓN TELLO, Francisco José y María Virginia Sanz y Sanz (1994): Estética y teoría de la arquitectura en tratados españoles del siglo XCIII. Consejo Superior de Investigaciones Científicas, Madrid.

MENÉNDEZ Y PELAYO, Marcelino (1944): Historia de las ideas estéticas en España. Editorial Glem, tomo IX, Buenos Aires

MORENO, Alfredo (editor y estudio preliminar) (1983): Conde de Superunda. Relación del gobierno. Perú 1745-1761. Consejo Superior de Investigaciones Científicas, Madrid.

PÉREZ-MALLAÍNA BUENO, Pablo Emilio (2001): Retrato de una ciudad en crisis. La sociedad limeña ante el movimiento sísmico de 1746. Consejo Superior de Investigaciones Científicas. Escuela de Estudios hispanoamericanos y Lima, Pontificia Universidad Católica del Perú, Instituto Riva-Aguiero, Sevilla y Lima.

RODRÍGUEZ G. DE CEBALLOS, Alfonso (1995): Joaquín de Churriguera y la primera cúpula de la Catedral Nueva de Salamanca. En Homenaje al profesor Martín Gonzáles. Valladolid, Universidad de Valladolid, Secretariado de Publicaciones, Valladolid. 